\title{
PENGARUH PEMUPUKAN N, P, DAN K TERHADAP PERTUMBUHAN DAN PRODUKSI DUA KULTIVAR GLADIOL (Gladiolus hybridus L.)
}

\author{
Rindang Andam Suri, Tri Dewi Andalasari, Sri Ramadiana \& Kushendarto \\ Jurusan Agroteknologi, Fakultas Pertanian Universitas Lampung \\ Jl. Prof. Soemantri Brodjonegoro, No.1 Bandar Lampung 35145 \\ E-mail:r.andamsuri@yahoo.co.id
}

\begin{abstract}
ABSTRAK
Bunga gladiol adalah salah satu bunga potong yang paling banyak dicari orang, baik sebagai bunga hias atau untuk perayaan hari besar karena bunga ini sangat menarik perhatian. Faktor yang perlu diperhatikan dalam budidaya gladiol adalah pemupukan. Tanaman gladiol memerlukan pemupukan agar tanaman tumbuh dengan cepat dan berproduksi dengan baik. Untuk mengoptimalkan produksi bunga potong ini, yaitu dengan menerapkan penggunaan pupuk tunggal yang dikombinasikan. Pada kenyataannya petani gladiol menggunakan pupuk tunggal, namun penggunaan dan ketersediaannya tidak seideal yang diinginkan. Teknik ini harus dikembangkan untuk dapat meminimkan pupuk yang mahal serta kelangkaan pupuk yang terjadi saat ini dan memberikan informasi kepada petani tentang jumlah penggunaan pupuk N, P, dan, K yang tepat pada gladiol. Penelitian ini dilaksanakan di kelurahan Gunung Terang, Gg. Swadaya 6 dari bulan Desember 2011 sampai April 2012. Penelitian ini dilaksanakan dengan menggunakan RKTS (factorial experiment) dengan dua faktor. Faktor pertama yaitu kultivar Gladiol yaitu 'Holland Putih' $\left(\mathrm{H}_{\mathrm{w}}\right)$ dan 'Holland Pink' $\left(\mathrm{H}_{\mathrm{p}}\right)$. Faktor kedua adalah aplikasi berbagai campuran pupuk tunggal, yaitu : tanpa pupuk $\left(\mathrm{A}_{0}\right)$, pupuk NP(Urea dan SP-36) $\left(\mathrm{A}_{1}\right)$, pupuk NK (Urea dan KCL) $\left(\mathrm{A}_{2}\right)$, pupuk PK (SP-36 dan KCL) (A $)$, dan NPK lengkap (Urea, SP-36, KCL) (A $)$. Setiap kombinasi perlakuan diulang tiga kali. Satuan percobaan dikelompokkan berdasarkan bobot umbi. Homogenitas ragam diuji dengan uji Bartlet dan aditvitas data dengan uji Tukey. Data diolah menggunakan sidik ragam dan dilanjutkan Uji Beda Nyata Terkecil (BNT) pada taraf nyata 5\%. Hasil penelitian menunjukkan bahwa (1) pemberian pupuk anorganik tidak berpengaruh terhadap pertumbuhan dan produksi gladiol. (2) Perbedaan kultivar berpengaruh nyata dan sangat nyata terhadap tinggi tanaman, diameter floret, bobot subang, jumlah subang, diameter subang, bobot basah berangkasan dan bobot kering berangkasan. Kultivar yang memberikan nilai tertinggi adalah Holland Pink $\left(\mathrm{H}_{\mathrm{p}}\right)$ jika dibandingkan dengan kultivar Holland Putih $\left(\mathrm{H}_{\mathrm{w}}\right)$. (3) tidak terjadi interaksi antara perbedaan kultivar dengan perlakuan pupuk anorganik terhadap semua peubah pengamatan.
\end{abstract}

Kata Kunci : gladiol, kombinasi pupuk, pemupukan.

\section{PENDAHULUAN}

Bunga gladiol (Gladiolus hybridus L.)adalah salah satu komoditas tanaman hias yang termasuk dalam keluarga Iridaceae. Tanaman ini berasal dari Afrika Selatan dan sebagian kecil spesies lainnya berasal dari Eurasia. Julukan lain dari bunga gladiol ini adalah Sword lily atau pedang kecil dikarenakan bentuknya yang menyerupai. Bunga gladiol memiliki banyak kultivar dengan beragam warna, ukuran dan bentuk bunga. Bunga gladiol ini adalah salah satu bunga potong yang paling banyak dicari orang, baik sebagai bunga hias atau untuk perayaan hari besar karena bunga ini sangat menarik perhatian. Kelebihan dari bunga potong gladiol adalah kesegarannya yang dapat bertahan sekitar 3-5 hari. (Herlina, 1991).

Di Indonesia bunga gladiol memiliki prospek dan nilai ekonomi urutan tertinggi ketiga dari tujuh jenis bunga potong komersil yang diperdagangkan di pasar dalam negeri yaitu mawar, krisan, gladiol, sedap malam, anthurium, dahlia, dan bunga lainnya (Rukmana, 2004). Berdasarkan data dari Badan Pusat Statistik (2010) produksi bunga potong gladiol pada tahun 2005 mencapai 14.512.619 tangkai, dan pada tahun 2008 menurun sampai hingga 8.524.252 dan kembali naik sebesar 10.064.082 tangkai pada tahun 2010 .

Faktor yang perlu diperhatikan dalam budidaya gladiol adalah pemupukan. Tanaman gladiol memerlukan pemupukan agar tanaman tumbuh dengan cepat dan dapat berproduksi dengan baik. Kekurangan salah satu atau beberapa unsur hara akan mengakibatkan pertumbuhan tanaman menjadi tidak normal. Sumber unsur hara dapat diperoleh dari pupuk organik ataupun pupuk anorganik. Pupuk organik disebut juga pupuk alam karena sebagian besar pupuk ini berasal dari alam. Pupuk anorganik (kimia) terbagi atas pupuk kimia alami dan pupuk kimia buatan. Unsur yang paling dominan 
yaitu N, P, dan K. Salah satu pupuk K yang terkenal adalah $\mathrm{KCl}$.

Pada kenyataannya petani gladiol menggunakan pupuk tunggal untuk mengoptimalkan produksi bunga potong yang satu ini, namun penggunaan dan ketersediaannya tidak seideal yang diinginkan. Kelangkaan pupuk yang terjadi saat ini merupakan suatu kendala yang dihadapi petani gladiol. Sehingga petani memerlukan informasi tentang jumlah penggunaan pupuk $\mathrm{N}$, P, dan, K yang tepat pada gladiol.

Gladiol memiliki berbagai jenis kultivar, setiap kultivar memiliki keunggulan masing-masing. Kultivar Holand putih dan kultivar Holand Pink berprospek dikembangkan karena masing-masing dari kultivar memiliki warna yang indah, floretnya yang banyak, dan bunga yang cukup besar. Pemilihan kultivar yang sesuai yang dikombinasikan dengan pupuk diharapkan efektif dalam mengoptimalkan pertumbuhan dan produksi gladiol. Berdasarkan uraian diatas telah dilakukan penelitian dengan judul "Pengaruh Pemupukan N, P dan $\mathrm{K}$ terhadap Pertumbuhan dan produksi Dua Kultivar Gladiol”. Tujuan dari penelitian ini untuk mengetahui pupuk, kultivar serta interaksi antara kombinasi pupuk dan kultivar untuk pertumbuhan dan produksi gladiol.

\section{METODE PENELITIAN}

Penelitian ini dilaksankan di kelurahan Gunung Terang, Gg. Swadaya 4 dari bulan Desember 2011 sampai April 2012. Bibit gladiol yang digunakan adalah kultivar Holland Pink dan Holland Putih berumur 2 bulan setelah panen subang. Rancangan yang digunakan yaitu Faktorial (RKTS). Faktor pertama yaitu kultivar gladiol, faktor kedua yaitu perlakuan pupuk Media $\left(\mathrm{A}_{0}\right)$, pupuk NP (Urea dan SP-36) (A ), pupuk NK (Urea dan KCL) $\left(\mathrm{A}_{2}\right)$, pupuk PK (SP-36 dan KCL) $\left(\mathrm{A}_{3}\right)$, dan NPK lengkap (Urea, SP-36, KCL) $\left(\mathrm{A}_{4}\right)$.

Setiap kombinasi perlakuan diulang tiga kali. Dosis pupuk yang digunakan yaitu : Urea sebanyak 0.5 g, SP-36 sebanyak $0.6 \mathrm{~g}$ dan KCL sebanyak $0.5 \mathrm{~g}$. Pemupukan pertama dilakukan pada saat tanaman membentuk $2-3$ helai daun, pemupukan kedua dilakukan saat munculnya bunga, dan pemupukan ketiga dilakukan setelah panen bunga.

\section{HASIL DAN PEMBAHASAN}

Hasil analisis ragam menunjukkan bahwa pemberian pupuk anorganik tidak berpengaruh nyata terhadap seluruh peubah pengamatan (Tabel 1).

Tabel 1. Analisis ragam pengaruh perbedaan pupuk anorganik dan kultivar terhadap pertumbuhan dan produksi gladiol.

\begin{tabular}{|c|c|c|c|}
\hline \multirow{2}{*}{ Peubah Pengamatan- } & \multicolumn{3}{|c|}{ Signifikasi } \\
\hline & $(\mathrm{A})$ & $(\mathrm{H})$ & $\mathrm{AxH}$ \\
\hline \multicolumn{4}{|l|}{ Vegetatif } \\
\hline Jumlah daun & $\operatorname{tn}$ & $*$ & $\operatorname{tn}$ \\
\hline Tinggi tanaman & $\operatorname{tn}$ & $* *$ & tn \\
\hline Panjang tangkai bunga & $\operatorname{tn}$ & tn & th \\
\hline Panjang floret & $\operatorname{tn}$ & tn & tn \\
\hline Diameter floret & $\operatorname{tn}$ & $*$ & tn \\
\hline Jumlah floret & $\operatorname{tn}$ & tn & tn \\
\hline \multicolumn{4}{|l|}{ Generatif } \\
\hline Bobot subang & $\operatorname{tn}$ & $* *$ & $\operatorname{tn}$ \\
\hline Jumlah subang & $\operatorname{tn}$ & $*$ & tn \\
\hline Diameter subang & $\operatorname{tn}$ & $* *$ & tn \\
\hline Jumlah kormel & $\operatorname{tn}$ & tn & tn \\
\hline Bobot kormel & $\operatorname{tn}$ & tn & $\operatorname{tn}$ \\
\hline Bobot basah berangkasan & $\operatorname{tn}$ & $* *$ & th \\
\hline $\begin{array}{l}\text { Bobot kering } \\
\text { berangkasan }\end{array}$ & tn & $* *$ & tn \\
\hline
\end{tabular}

Keterangan: $\mathrm{A}=$ Pupuk Anorganik, $\mathrm{H}=$ Kultivar, $\mathrm{AxH}=$ Interaksi, $\mathrm{tn}=$ tidak nyata, ${ }^{*}=$ nyata pada $\alpha_{0,05}$. 
Hasil penelitian menunjukan bahwa kultivar Holland Pink menghasilkan tinggi sebesar 109,14 cm, yang berbeda dengan Holland Putih sebesar 83,19 cm (Gambar 1). Jumlah daun kultivar Holland Pink menghasilkan jumlah daun 8,74 buah, yang berbeda dengan Holland Putih sebesar 8,3 buah (Gambar 1), dan diameter floret, kultivar Holland Putih menghasilkan diameter floret 9,54 cm, yang berbeda dengan Holland Pink sebesar 9,11 cm (Gambar 1 dan Gambar 2).

Hasil penelitian menunjukan bahwa pemberian pupuk anorganik tidak berpengaruh terhadap panjang tangkai bunga dan panjang dan jumlah floret (Tabel 2). Dari hasil penelitian diketahi bahwa respon kultivar Holland Pink lebih baik dari pada Holland Putih dalam bobot subang, jumlah subang, diameter subang, dan bobot kering brangkasan. Holland Pink menghasilkan bobot subang sebesar 25,91 g, jumlah subang 1,15 buah, diameter subang $4,14 \mathrm{~cm}$, dan bobot kering brangkasan $9,83 \mathrm{~g}$, sedangkan Holland putih menghasilkan bobot subang sebesar 12,95 g, jumlah subang 1,02 buah, diameter subang $3,45 \mathrm{~cm}$, dan bobot kering brangkasan $4,11 \mathrm{~g}$ (Gambar 3).

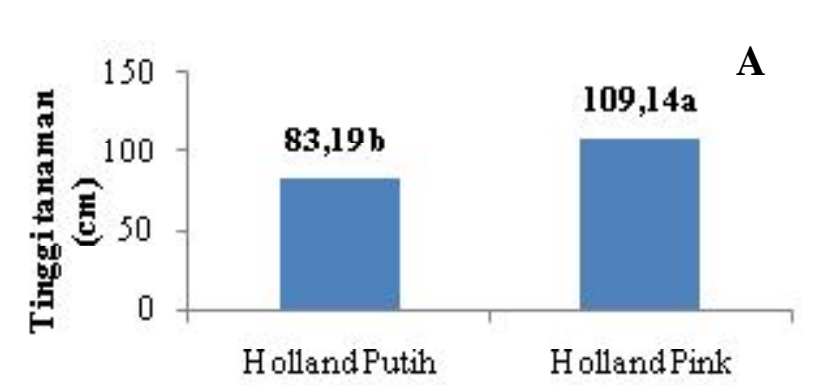

Kultivar

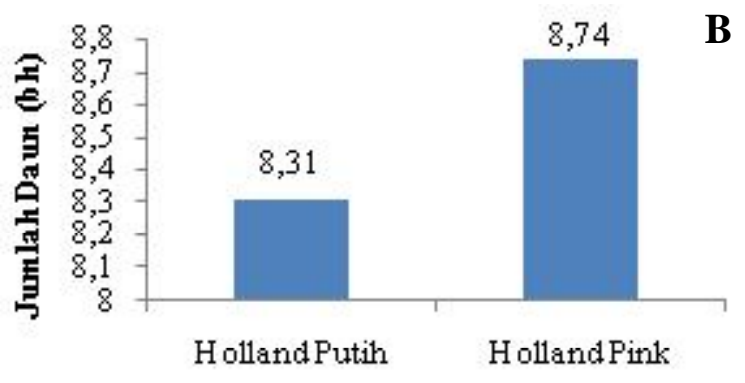

Kultiv ar

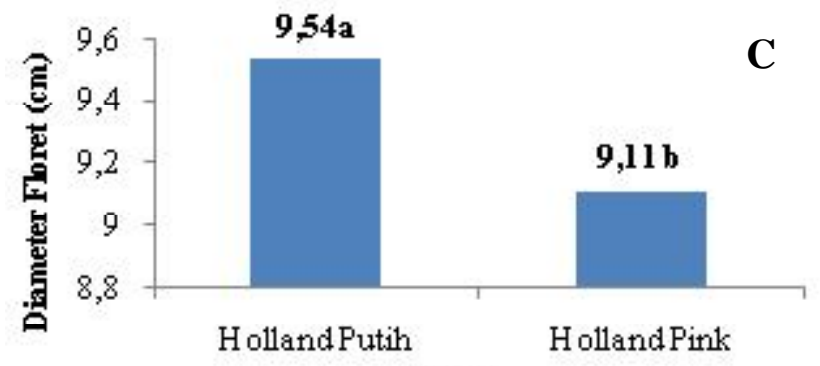

Kultiv ar

Gambar 1. Diagram pengaruh kultivar gladiol terhadap tinggi tanaman (A), jumlah daun (B), dan diameter floret (C). Huruf yang sama dibelakang angka menunjukan tidak berbeda nyata pada uji $\mathrm{BNT} \alpha_{0,05}$. Nilai BNT $\alpha_{0,05}$ tinggi tanaman $=4,43$ dan BNT $\alpha_{0,05}$ diameter floret $=0,42$.
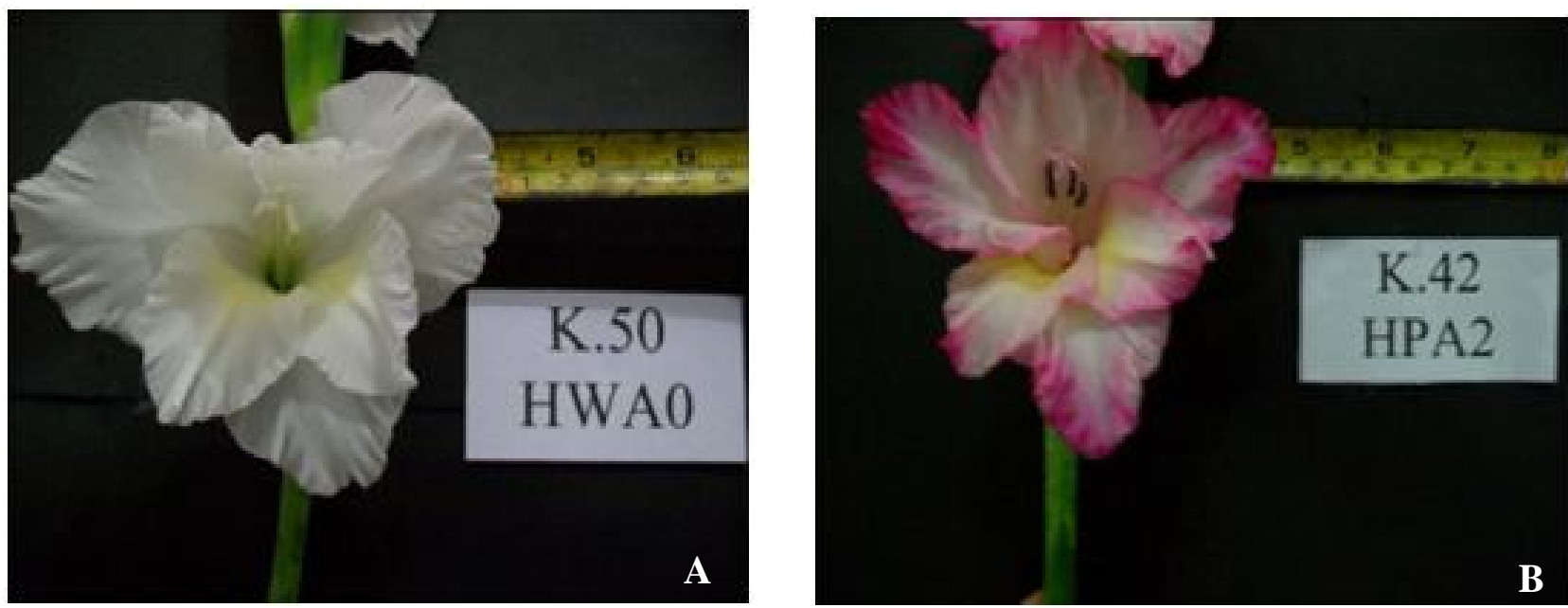

Gambar 2. Tampilan diameter floret dua kultivar gladiol. A (kultivar Holland Putih) dan B (kultivar Holland Pink) 
Tabel 2. Pengaruh pupuk dan perbedaan kultivar terhadap panjang tangkai bunga, panjang floret, dan jumlah floret tanaman gladiol

\begin{tabular}{|c|c|c|c|}
\hline Kultivar & Panjang tangkai bunga $(\mathrm{cm})$ & Panjang floret $(\mathrm{cm})$ & Jumlah Floret (ku ntum) \\
\hline A0 & $83,25 \mathrm{a}$ & $44,58 \mathrm{a}$ & $12,92 \mathrm{a}$ \\
\hline A1 & $76,83 \mathrm{a}$ & $41,25 \mathrm{a}$ & $12,25 \mathrm{a}$ \\
\hline A2 & $78,31 \mathrm{a}$ & $40,21 \mathrm{a}$ & $11,47 \mathrm{a}$ \\
\hline A3 & $80,28 \mathrm{a}$ & $42,44 \mathrm{a}$ & $12,78 \mathrm{a}$ \\
\hline A4 & 83,78 a & $43,58 \mathrm{a}$ & $12,89 \mathrm{a}$ \\
\hline BNT 0,05 & 8,77 & 7,72 & 1,98 \\
\hline Kultivar & Panjang tangkai bunga $(\mathrm{cm})$ & Panjang floret $(\mathrm{cm})$ & Jumlah Floret (ku ntum) \\
\hline Holland Putih $\left(\mathrm{H}_{\mathrm{W}}\right)$ & $81,16 \mathrm{a}$ & $44,49 \mathrm{a}$ & $12,14 \mathrm{a}$ \\
\hline Holand Pink $\left(\mathrm{H}_{\mathrm{P}}\right)$ & $79,81 \mathrm{a}$ & $40,34 \mathrm{a}$ & $12,78 \mathrm{a}$ \\
\hline BNT 0,05 & 5,55 & 4,88 & 1,25 \\
\hline
\end{tabular}

Keterangan: angka-angka yang diikuti oleh huruf yang sama dalam satu kolom tidak berbeda nyata pada uji BNT $\alpha_{0,05}$.

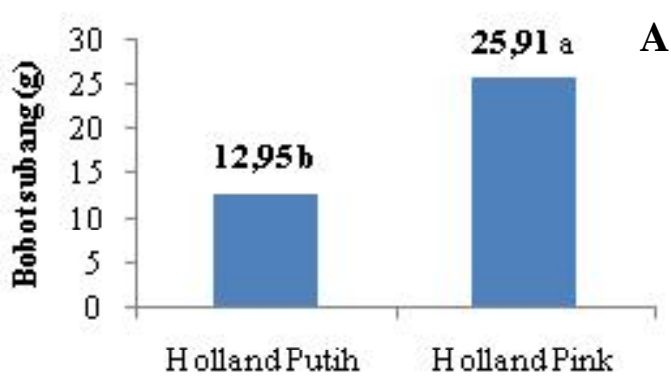

Kultivar

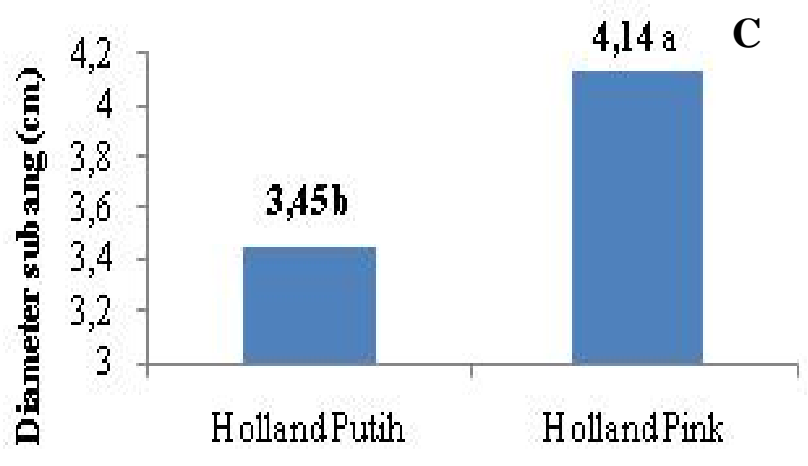

Kultivar

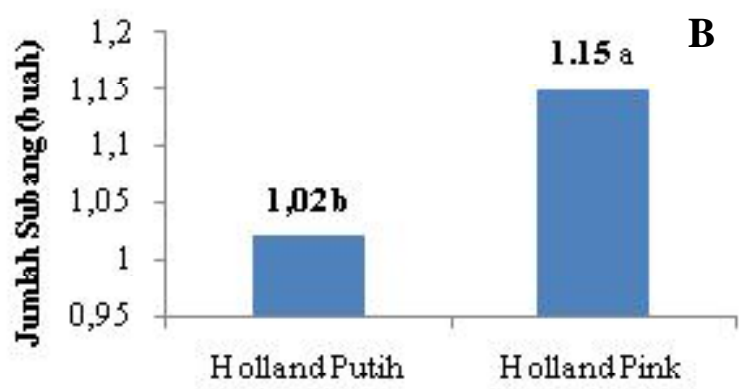

Kultivar

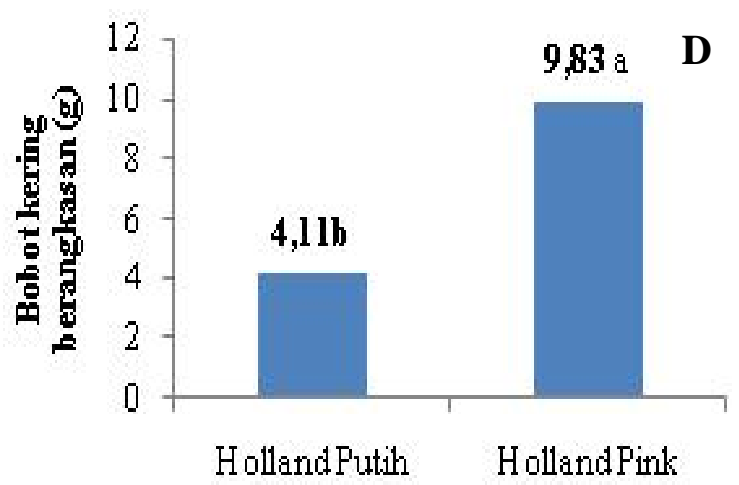

Kultivar

Gambar 3. Diagram pengaruh kultivar gladiol terhadap bobot subang (A), jumlah subang (B), diameter subang (C), dan bobot kering brangkasan (D). Huruf yang sama dibelakang angka menunjukan tidak berbeda nyata pada uji BNT $\alpha_{0,05}$. Nilai BNT $\alpha_{0,05}$ bobot subang $=4,59$, nilai BNT $\alpha_{0,05}$ jumlah subang $=0,10$, nilai BNT $\alpha_{0,05}$ diameter subang $=0,40$, dan nilai BNT $\alpha_{0,05}$ bobot kering brangkasan $=2,04$.

Hasil penelitian menunjukan bahwa aplikasi pupuk annorganik tidak berpengaruh nyata terhadap jumlah dan bobot kormel pada kedua kultivar gladiol yang digunakan (Tabel 3).

Kultivar Holland Pink memiliki tinggi tanaman yang lebih baik dari pada kultivar Holland Putih. Herlina (1991) menyatakan bahwa pertumbuhan dari masing masing kultivar mempengaruhi bentuk floret, panjang tangkai bunga, diameter floret apabila penggunaan ukuran subang bibit yang berbeda serta kesuburan pada 
Tabel 4. Pengaruh pupuk dan perbedaan kultivar terhadap jumlah kormel dan bobot kormel tanaman gladiol.

\begin{tabular}{lcc}
\hline Pupuk & Jumlah kormel (buah) & bobot kormel $(\mathrm{g})$ \\
\hline A0 & $11,81 \mathrm{a}$ & $3,03 \mathrm{a}$ \\
A1 & $9,14 \mathrm{a}$ & $2,57 \mathrm{a}$ \\
A2 & $5,55 \mathrm{a}$ & $1,96 \mathrm{a}$ \\
A3 & $5,56 \mathrm{a}$ & $2,59 \mathrm{a}$ \\
A4 & $10,64 \mathrm{a}$ & $4,49 \mathrm{a}$ \\
\hline BNT 0,05 & 9,24 & 2,66 \\
\hline Kultivar & Jumlah kormel & bobot kormel $(\mathrm{g})$ \\
\hline Holland Putih $\left(\mathrm{H}_{\mathrm{W}}\right)$ & $10,10 \mathrm{a}$ & $2,40 \mathrm{a}$ \\
Holand Pink $\left(\mathrm{H}_{\mathrm{P}}\right)$ & $6,98 \mathrm{a}$ & $3,45 \mathrm{a}$ \\
\hline BNT 0,05 & 5,84 & 1,68 \\
\hline
\end{tabular}

Keterangan: angka-angka yang diikuti oleh huruf yang sama dalam satu kolom tidak berbeda nyata pada uji BNT $\alpha_{0,05}$

tanaman berbeda. Menurut Indrastuti et al. (2010), semakin besar ukuran subang berarti cadangan makanan untuk mendukung pertumbuhan juga semakin besar. Bobot subang berpengaruh pada pertumbuhan tanaman gladiol selanjutnya, karena ditentukan oleh jumlah makanan yang berasal dari subang (Soedarjo, 2010).

Perlakuan pupuk anorganik tidak berpengaruh terhadap semua peubah pengamatan, serta tidak terjadi interaksi antara perlakuan pupuk dengan kultivar. Hal ini diduga bahwa dengan media yang digunakan (tanah + arang sekam + kotoran kambing) merupakan campuran yang menyediakan pupuk maksimal. Penambahan bahan organik pada media tanam menghasilkan jumlah floret lebih banyak pada kultivar Kaifa, dibandingkan dengan jumlah floret pada kultivar Clara menurut Astuti (2007). Menurut Nasihin (2012), pupuk organik yg berasal dari kotoran kambing dapat meningkatkan kandungan $\mathrm{N}$ dan $\mathrm{P}$ tanah, memperbaiki sifat fisik, kimia dan biologi tanah dan memacu pertumbuhan akar. Selain itu, arang sekam memiliki kemampuan yang baik untuk mengikat air dan unsure hara yang baik, dan lebih steril dibandingkan dengan media pasir (Silvina, 2008).

\section{KESIMPULAN}

Berdasar hasil penelitian dapat disimpulkan bahwa pemberian pupuk anorganik $\mathrm{N}$, $\mathrm{P}$, dan $\mathrm{K}$ dengan dosis $1.5 \mathrm{~g}$ tidak berpengaruh terhadap semua peubah pengamatan. Kultivar Holland Pink $\left(\mathrm{H}_{\mathrm{P}}\right)$ menghasilkan tinggi tanaman, bobot subang, jumlah subang, diameter subang, bobot basah berangkasan dan bobot kering berangkasan yang lebih besar dibandingkan dengan kultivar Holland Putih $\left(\mathrm{H}_{\mathrm{w}}\right)$. Tidak terdapat interaksi antara perlakuan pupuk anorganik dengan perbedaan kultivar terhadap semua peubah pengamatan.

\section{DAFTAR PUSTAKA}

Astuti, Y. 2007. Pengaruh Jenis Bahan Organik Pada Produksi Tiga Varietas Gladiol (Gladiolus hybridus L.). (Skripsi). Universitas Lampung. Bandar Lampung. $70 \mathrm{hlm}$.

Badan Pusat Statistik. 2010. Produksi Tanaman Hias Di Indonesia Periode 2005 - 2009. http:// www.bps.go.id/images/bps.ico. Diakses tanggal 8 oktober pukul 06.40.

Herlina, D. 1991. Gladiol. Penebar Swadaya. Jakarta. $118 \mathrm{hlm}$.

Indrastuti, B., Andalasari, T.D., dan Timotiwu, P. 2010. Pematahan Dormansi Dua Varietas Gladiol (Gladiolus hybridus L.) dengan Karbida $\left(\mathrm{Cac}_{2}\right)$ dan Benziladenin (Ba). Prosiding Seminar Nasional Teknologi Tepat Guna Agroindustri. Politeknik Negeri Lampung. Lampung.

Nasihin, Y. 2012. Teknik Peningkatan Produksi Benih Krisan Dengan Aplikasi Pupuk Kambing. Balai Penelitian Tanaman Hias. Buletin Teknik Pertanian Vol. 17, No. 01. 22 - 25 hlm.

Rukmana, R. 2004. Gladiol Prospek Agribisnis dan Teknik Budidaya. Kanisius Yogyakarta. 
Silvina, F., Syafrinal. 2008. Penggunaan Medium Tanam dan Konsentrasi Pupuk Cair pada Pertumbuhan dan Produksi Mentimun Jepang secara Hidroponik. SAGU. Vol. 7 No. 1. ISSN 14124424. 7 - $12 \mathrm{hlm}$.
Soedarjo, M., S. Wuryaningsih. 2010. Respon Beberapa Varietas Gladiol Terhadap Pemupukan N dan K. J. Hort. 20 (2). Balai Penelitian Tanaman Hias. Cianjur, 2 September 2010. 148 - 156 hlm. 